\title{
Fungal Endophytes of Boswellia Serrata Roxb. (Burseraceae), a Medicinal Tree Species
}

\author{
Sunayana, N. and Prakash, H. S. \\ Department of Studies in Biotechnology, University of Mysore, Manasagangotri, Mysore -570 006, Karnataka, \\ India.
}

\begin{abstract}
Fungal endophytes were isolated from Boswellia serrata, an ethnopharmacologically important tree species used in ayurvedic medicines to treat inflammation. Isolations were made from symptomless bark, inner bark, twig and leaf samples collected from Chamundi Hills, Mysore. A total of 530 isolates were recovered from 3000 tissue fragments of B. serrata. Of these isolates, 522 sporulated and belonged to 17 genera based on morphological characteristics. Among the 17 genera, mitosporic fungi were dominant. Myrothecium verrucaria (10.37\%) was the dominant species followed by Phoma spp. (9.24\%). High colonization rates of endophytic fungi were found in twigs followed by inner bark, bark and leaf.
\end{abstract}

Keywords: Boswellia serrata, Endophytes, colonization frequency, diversity index

\section{Introduction}

Boswellia serrata Roxb. (Family-Burseraceae) also known as 'Salai Guggal' in Sanskrit is one of the most important tree in the Indian system of traditional medicine. This is a deciduous, medium-sized tree, abundantly growing in dry hilly tracts of India. It yields oleo-gum-resin called 'Salai Guggal' used for a variety of therapeutic purposes such as cancer, inflammation, arthritis, asthma, psoriasis, colitis, crohn's diseases and hyperlipidemia [1]. The major bioactive constituents of $B$. serrata are triterpenoids, boswellic acid and 11-keto$\beta$-boswellic acid [2]. Salai guggal contains 8-9\% essential oil, 20-23\% gum and about 50\% resin. Gum contains different sugars like D-galactose, D-arabinose, D-xylose and D-mannose. It also contains volatile oil and uronic acids. A range of triterpene acids such as Boswellic acids, Acetyl-boswellic acid, keto-boswellic acid and acetyl-keto-boswellic acid have been isolated and are responsible for its medicinal value [3].

In recent years, the microbes residing in the plant tissues called 'Endophytes' have gained importance as components of screening program for therapeutics. These organisms have the ability to produce and mimic the secondary metabolites produced by the plant. The term "Endophyte" was coined by the German scientist Heinrich Anton De Bary, and is used to define fungi or bacteria occurring inside plant tissues without causing any apparent symptoms in the host [4]. Every plant species examined till date harbours endophytic fungi [5]. Endophytes produce bioactive compounds like Taxol, a diterpenoid compound with anticancer properties, which was first isolated from Taxus brevifolia [6]. Likewise few other endophytic fungi are found to produce economically important bioactive compounds like Phomol [7]. Thus, if a microbial source of the drug would be available, it would eliminate the need to harvest and extract the slow growing and relatively rare trees for the drug. The price for the drug would then be reduced. Some endophytic fungi belonging to different genera such as Taxomyces andreanae, Pestalotiopsis microspora, Alternaria alternata, Periconia sp., Pithomyces sp., Monochaetia sp., Seimatoantlerium nepalense are reported to produce Taxol [8]. The endophytic fungi are of biotechnological importance as sources of new pharmaceutical compounds, secondary metabolites, agents of biological control and other useful characteristics.

No reports are available on the endophytes from B. serrata, so this tree species is selected for the study due to its immense medicinal properties. This study provides first information on the isolation and identification of fungal endophytes from $B$. serrata.

\subsection{Collection of plant material}

\section{Material and Methods}

Bark, Inner bark, twig and leaf samples of Boswellia serrata were collected from five different healthy trees growing in the region of Chamundi Hills, Mysore (Location $12^{\circ} 18^{\prime \prime} 25^{\prime} \mathrm{N}, 76^{\circ} 38^{\prime \prime} 58^{\prime} \mathrm{E}$ ) Karnataka in Southern India. Chamundi Hill supports the deciduous vegetation. Bark pieces $(5.0 \mathrm{~cm}$ X $5.0 \mathrm{~cm})$ from the trunk were cut 1.5-2.0 m above the ground level with the help of sterile machete. The outer part was considered as bark and towards the center or pith is taken as inner bark. The samples were placed in polythene bags, labeled, transferred in ice box to the laboratory and placed in a refrigerator at $4^{\circ} \mathrm{C}$. The samples were processed within 24 $\mathrm{h}$ of collection. 
Fungal endophytes of Boswellia serrata Roxb. (Burseraceae), a medicinal tree species

\subsection{Isolation, identification and preservation of endophytes}

The samples were washed thoroughly in running water before processing. Bark, inner bark, twig and leaf pieces/samples were surface sterilized by immersing in $70 \%$ ethanol (v/v) for one min and $3.5 \% \mathrm{NaOCl}$ $(\mathrm{v} / \mathrm{v})$ for three min, then rinsed with sterile water thrice and allowed to surface dry under sterile conditions. Bits of $1.0 \times 1.0 \mathrm{~cm}$ size were excised with the help of a sterile blade. Two hundred segments of each of bark, inner bark, twig and leaf were placed on water agar (15 g/ l) (WA) medium supplemented with Streptomycin (100 $\mathrm{mg} / \mathrm{l}$ ) contained in $9 \mathrm{~cm}$ diameter Petri dishes. Ten to fifteen segments were placed on solidified $20 \mathrm{ml} \mathrm{WA}$ medium in each Petri dish. The Petri dishes were incubated at $22^{\circ} \mathrm{C}$ with $12 \mathrm{~h}$ light and dark cycles upto 3-4 weeks [9]. After incubation, individual fungal colonies were picked from the edge with a sterile fine tipped needle and transferred onto potato dextrose agar (PDA) medium for further identification. The fungal endophyte that did not sporulate was inoculated onto sterilized banana leaf bit $\left(1 \mathrm{~cm}^{2}\right)$ impregnated on agar to ensure sporulation [10]. The endophytic identification was done based on the conidial morphology and conidial characters. All endophytic isolates have been maintained in cryovials on PDA layered with $15 \%$ glycerol $(\mathrm{v} / \mathrm{v})$ at $-80^{\circ} \mathrm{C}$ in an Ultra freezer (Cryoscientific Pvt. Ltd., Chennai, India) at the Department of Studies in Biotechnology, University of Mysore, Mysore, India.

\subsection{Data analysis}

The colonisation density, colonisation rates and isolation rates of Fungal Diversity was calculated as the percentage of segments infected by one or more isolate(s) from the total number of segments of each tissue plated following the method of [11].

Total no. of bits/sections in a sample yielding $\geq 1$ isolate

Colonisation rate $=$ Total no. of bits/sections in that sample

Total no. of isolates yielded by a given sample

Isolation rate $=\quad$ Total no. of isolates yielded by a given sample

Total no. of bits/sections in that sample

The relative frequency of colonization (\% CF) was calculated as the number of isolates of a taxon from each segments divided by the total number of segments plated X 100 [12] and dominant endophytes were calculated as percentage colony frequency divided by sum of percentage of colony frequency of all endophytes $\mathrm{X} 100$ [13].

\subsection{Species diversity indices}

Shannon diversity index $\left(\mathrm{H}^{\prime}\right)$, Shannon evenness index $\left(\mathrm{J}^{\prime}\right)$ and Simpson diversity index (D) were calculated for the evaluation of fungal species richness of endophytes isolated from different types of sample of B. serrata using the Shannon calculator [14]. It was done based on the data provided in Table 2. The endophyte species present in the particular sample type was taken as 1 and the same endophyte absent in the other sample type was taken as 0 and represented in Table 2.

III. Tables:

Table 1: Colonization and Isolation rates of endophytic fungi in Boswellia serrata

\begin{tabular}{|c|c|c|c|c|c|}
\hline & BARK* & INNER BARK* & TWIG* & LEAF* & TOTAL \\
\hline No. of samples yielding fungi & 108 & 120 & 175 & 70 & 473 \\
No. of Isolates & 120 & 138 & 194 & 78 & 530 \\
Colonization Rate (\%) & 14.4 & 20.4 & 24.1 & 11.46 & 17.6 \\
Isolation Rate & 0.13 & 0.21 & 0.27 & 0.12 & 0.19 \\
\hline
\end{tabular}

*Based on 750 bits plated per sample

Table 2: Frequency of endophytic fungi isolated from bark, inner bark, twig and leaf samples of B. serrata

\begin{tabular}{|l|c|c|c|c|c|c|}
\hline \multirow{2}{*}{ Endophytic Fungi } & \multicolumn{5}{|c|}{ \% of Colonization Frequency } & \\
\cline { 2 - 7 } & & & & & & $\begin{array}{c}\text { Frequency } \\
\text { Of } \\
\text { Dominant } \\
\text { Endophyte }\end{array}$ \\
\cline { 2 - 7 } & $\mathrm{B}^{*}$ & IB* & T* & $\mathrm{L}^{*}$ & Total & 6.60 \\
\hline Acremonium strictum & - & 1.16 & - & - & 35 & 3.77 \\
\hline Botrytis sp. & - & - & - & 0.66 & 20 & 0.75 \\
\hline Fusarium pallidoroseum & - & - & 0.13 & - & 4 & 5.09 \\
\hline Memnoniella sp. & 0.7 & - & 0.2 & - & 27 & 10.37 \\
\hline Myrothecium verrucaria & - & - & 1.5 & 0.33 & 55 & \\
\hline
\end{tabular}


Fungal endophytes of Boswellia serrata Roxb. (Burseraceae), a medicinal tree species

\begin{tabular}{|l|c|c|c|c|c|c|}
\hline Nigrospora oryzae & 0.73 & 0.76 & - & - & 45 & 8.49 \\
\hline Pestolotiopsis spp. & 1.6 & - & - & - & 48 & 9.05 \\
\hline Phoma exigue & 0.43 & 1.1 & 0.1 & - & 49 & 9.24 \\
\hline Phoma lingam & 0.03 & - & 0.43 & - & 19 & 3.58 \\
\hline Phoma sorghina & 0.06 & 0.43 & 0.06 & & 17 & 3.20 \\
\hline Phomopsis sp. & - & - & 0.36 & - & 11 & 2.07 \\
\hline Pithomyces sp. & - & 0.33 & - & - & 10 & 1.88 \\
\hline Trichothecium roseum & - & - & 0.56 & - & 17 & 3.20 \\
\hline Aspergillus flavus & - & 0.5 & - & 1 & 45 & 8.49 \\
\hline Aspergillus fumigatus & 0.06 & 0.13 & 0.9 & 0.36 & 44 & 8.30 \\
\hline Aspergillus nidulance & - & - & 1 & 0.16 & 35 & 6.60 \\
\hline Aspergillus niger & 0.36 & 0.16 & 0.76 & 0.06 & 41 & 7.73 \\
\hline Mycelia sterilia & - & - & 0.26 & - & 8 & 1.50 \\
\hline Total CF \% & $\mathbf{1 6}$ & $\mathbf{1 8 . 4}$ & $\mathbf{2 5 . 8 6}$ & $\mathbf{1 0 . 4}$ & & \\
\hline $\begin{array}{l}\text { Total No. of Isolates } \\
\text { Recovered }\end{array}$ & $\mathbf{1 2 0}$ & $\mathbf{1 3 8}$ & $\mathbf{1 9 4}$ & $\mathbf{7 8}$ & $\mathbf{5 3 0}$ & \\
\hline $\begin{array}{l}\text { Shannon-Wiener Diversity } \\
\text { Index }\end{array}$ & $\mathbf{1 . 6 0}$ & $\mathbf{1 . 8 6}$ & $\mathbf{2 . 1 6}$ & $\mathbf{1 . 3 8}$ & & \\
\hline Species Richness (S) & $\mathbf{8}$ & $\mathbf{8}$ & $\mathbf{1 2}$ & $\mathbf{6}$ & & \\
\hline $\begin{array}{l}\text { Simpson Diversity Index } \\
\text { (D) }\end{array}$ & $\mathbf{0 . 2 4}$ & $\mathbf{0 . 1 7}$ & $\mathbf{0 . 1 3}$ & $\mathbf{0 . 3 2}$ & & \\
\hline
\end{tabular}

*Based on 200 bits. B: Bark IB: Inner Bark T: Twig $\quad$ L: Leaf *Simpson's index of diversity (D)

\# Total species richness is a measure of genera per location/ sample type.

FIGURE:
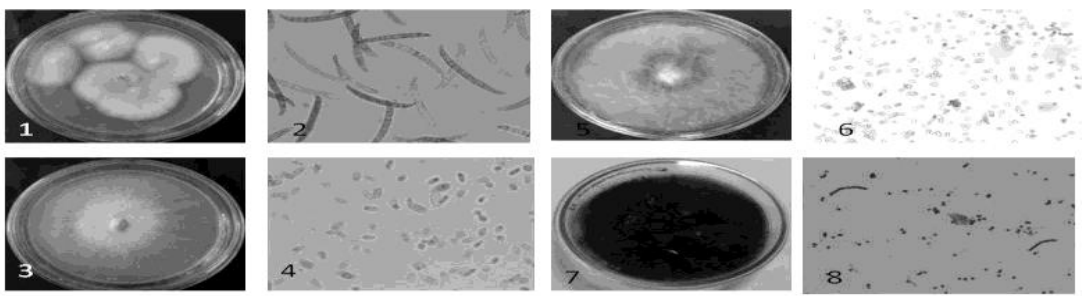

Fig 1: Colony morphology and conidial characters of some fungal endophytes isolated from the medicinal plant Boswellia serrata Fusarium, palladorosentm colony (1) and conidial colony (5) and conidial characteristics (6): Memmoniella sp. colony (7) and conidial characteristics (s)

IV. Result and Discussion

The present study gives first hand information on the fungal endophytes of B. serrata. A total of 530 isolates of endophytic fungi were recovered from 3000 tissue segments of B. serrata. Of the 530 fungal isolates recovered, 522 could sporulate and were identified to 17 genera based on morphological characteristics. Among the 17 genera, 16 belonged to mitosporic fungi (70.58\%), four Ascomycetes (23.52\%) and one Coelomycetes $(5.88 \%)$. The other eight isolates $(47.05 \%)$ did not sporulate (Table 2). Thus the mitosporic fungi were the major group of endophytes in B. serrata. Such dominance of mitosporic endophytes has also been reported from the bark segments in C. magna and T. arjuna [15]. Endophytic microorganisms are a significant reservoir of novel bioactive secondary metabolites. The number of secondary metabolites produced by fungal endophytes is larger than that of a:iy other endophytic microorganism class. These endophytic fungi are obviously a rich and reliable source of chemically novel bioactive compounds with huge medicinal and agricultural potential [16].

The colonization rate $(11.46 \%$ to $24.1 \%)$ and isolation rate $(0.12 \%-0.27 \%)$ of endophytic fungi obtained from $B$. serrata in the present study (Table 1). [17] reported that the colonization rate of endophytic fungi was 55.4\% in Quercus ilex L. and 64.6\% in Quercus faginea [18] pointed out that the colonization rate of endophytic fungi was $100 \%$ in the perennial twigs of Betula pubescens Ehrh. Similarly, we also found that the colonization rate of endophytic fungi was high in the twig (24.1\%). Such a colonization frequency has also 
Fungal endophytes of Boswellia serrata Roxb. (Burseraceae), a medicinal tree species

been previously reported in Azardirachta indica (Neem), where in a total of 77 endophytes belonging to 15 genera were isolated from the inner bark of neem by [19].

One of the possible reasons for the differences in the colonization rates between plant parts is the structure and substrate which influence the colonization and distribution of endophytic fungi [20]. Our studies also support these findings where the number of endophytic fungi was higher in twigs followed by inner bark, bark and leaves. However, the overall colonization frequencies differed with different organs. The number of species occurring in the inner bark and the twig region was almost the same; yet, the twig was more densely colonized by the endophytes as evidenced by the total CF\%. Similar results have been observed for Azadirachta indica [21]. However the colonization frequency reported according to [22] was $62.5 \%$ where a total of 32 species belonging to 21 genera were isolated from inner bark of Prosopis cineraria tree.

Among the endophytes, M. verrucaria $(10.37 \%)$ was dominant followed by Phoma spp. $(9.24 \%)$. The total colonization frequency ranged from a high of $10.37 \%$ from M. verrucaria and low of $0.75 \%$ from Fusarium pallidoroseum. The other endophytes recovered from B. serrata are Acremonium sp., Botrytis sp., Memnoniella sp., Phomopsis sp., Pithomyces sp., Trichothecium roseum and Aspergillus sp. (Fig.1). These endophytes have also been reported as endophytes in earlier studies [23]. Aspergillus sp. belonging to Ascomycetes was isolated from the B. serrata as an endophyte, which has earlier been reported as an endophyte on different host group by [24] in Melia azadirach and Prosopis cineraria respectively.

Among the plant parts, the colonization as well as the isolation rates of endophytic fungi was higher in twigs followed by inner bark, bark and leaf samples. Such a study corroborates with the findings of [25] who have reported that colonization and isolation rates of endophytic fungi were conspicuously higher in twigs than those in leaves in the six plants examined. The studies of [26] and [15] have showed that the bark samples contained more endophytes than twig samples in Terminalia arjuna and Crataeva magna. [27] also stated that the overall colonization rate in the leaves was found to be significantly higher than those in root bark, root xylem, flowers and twig bark. Same results were reported in many previous endophyte studies.

Total species richness as a measure of number of genera per sample was recorded. The colonization of some endophytic taxa and their density in twig segments was more when compared to other parts. Two separate indices, the Shannon-Wiener index and the Simpon's diversity index, were used to determine the species diversity of fungal endophytes colonized in bark, inner bark, twig and leaf using the Shannon calculator (Table 2).

Endophytes of twig exhibited the highest diversity index (Shannon diversity: 2.16, Simpsons' diversity: 0.137, Species richness: 12) and leaf had the lowest diversity index. [25] found higher Shannon-Weaver diversity indices of endophytic fungi in twigs than in leaves of the six plants reported, likewise Simpson dominance index and Shannon diversity index showed the same result as above [27]. Other findings have supported that the leaf samples showed more diversity of endophytic fungi than the stem and bark samples [28]. Simpson's diversity index value range between 0 and 1, where an increasing index value equates to an increase in species diversity. Thus the endophytes isolated from twigs exhibited greater diversity compared to the endophytes of the other plant parts examined.

To conclude, endophytic fungi are sources for new secondary metabolites with useful biological activity. Interest in fungal endophytes is largely due to their chemical diversity which represents a virtually untapped source of chemical reservoir that finds use in agriculture and therapeutics. The endophytes provide an alternative source of bioactive secondary metabolites. Further work regarding the isolation and characterization of the bioactive compound from the selected endophytic fungi is under progress.

\section{Acknowledgments:}

The authors acknowledge Indian Council of Medical Research, New Delhi for the financial support, Mr. Sampath Kumar for helping in the identification of the medicinal plant and Dr. M. S. Nalini for helping in the preparation of manuscript.

\section{References:}

[1] A. Menon, and A. Kar, (1970)Analgesic and psychopharmacological effects of the gum resin of Boswellia serrata. Planta Medica 19(3), 1970, 23-28.

[2] M. Babita, S.C. Taneja, and V.K. Sethi, Two triterpenoids from Boswellia serrata gum resin. Phytochemistry 39, 1995, 453-455.

[3] H.W. Zhang, Y.C. Song, and R.X. Tan, Biology and chemistry of endophytes. Natural Product 23, 2006b, 753-771.

[4] D. Wilson, Endophyte: the evolution of a term, and clarification of its use and definition. Oikos 73, 1995, 274-276.

[5] G. Strobel, Muscodor albus and its biological promise. Journal of Industrial Microbiology and Biotechnology 33, 2006, 514-522.

[6] M.C. Wani, H.L. Taylor, M.E. Wall, P. Coggon, and A.T. McPhail, Plant antitumor agents. VI. The isolation and structure of taxol, a novel antileukemic and antitumor agent from Taxus brevifolia. Journal of American Chemistry of Society 93, 1971, 2325-2327.

[7] F. Redko, M. Clavin, D. Weber, T. Anke, and V. Martino, Search for active metabolites of Erythrina crista- galli and its endophytic Phomopsis sp. Molecular and Medicinal Chemistry 10, 2006, 24-26.

[8] J.Y. Li, R.S. Sidhu, A. Bollon, and G.A. Strobel, Stimulation of Taxol Production in liquid cultures of Pestolotiopsis microspora. Mycological Research 102, 1998, 461-464.

[9] T.S. Suryanarayanan, Light-incubation: a neglected procedure in mycology. The Mycologist, 6, 1992, 144

[10] T. Matsushima, Icons microfungorum as matushima lectorum. Published by the author, Kobe, Japan. 78 1975, 32-34. 
Fungal endophytes of Boswellia serrata Roxb. (Burseraceae), a medicinal tree species

[11] O. Petrini, and P.J. Fisher, A comparative study of fungal endophytes in xylem and whole stems of Pinus sylvestris and Fagus sylvatica. Transactions of the British Mycological Society 91, 1988, 233-238.

[12] P.J. Fisher, and O. Petrini, Location of fungal endophytes in tissue of Suaeda fruticosa: A preliminary study. Transactions of the British Mycological Society 89, 1987, 246-249.

[13] V. Kumaresan, and T.S. Suryanarayanan, Endophyte assemblages in young, mature and senescent of Rhizophora apiculata: evidence for the role of endophytes in mangrove litter degradation. Fungal Diversity 9, 2002, 81-91.

[14] H.J. Zar, Biostatistical analysis. ${ }^{\text {th }}$ Edition, Pearson Education Pvt. Ltd, Delhi, 2004, 1-663.

[15] M.S. Nalini, B. Mahesh, M.V. Tejesvi, H.S. Prakash, V. Subbaiah, K.R. Kini, and H.S. Shetty, Fungal endophytes from the three leaved Caper, Crataeva magna (Lour) DC. (Capparidaceae). Mycopathalogia 59, 2005, 245-249.

[16] G. Strobel, B. Daisy, U. Castillo, and J. Harper, Natural products from endophytic microorganisms. Journal of Natural Product 67, 2004, 257-268.

[17] J. Collado, G. Platas, and F. Peláez, Host specificity in fungal endophytic populations of Quercus ilex and Quercus faginea from central Spain. Nova Hedwigia 71: 2000, 421-430.

[18] N. Barengo, T.N. Sieber, and O. Holdenrieder, Diversity of endophytic mycobiota in leaves and twigs of pubescent birch (Betula pubescens). Sydowia 52, 2000, 305-320.

[19] B. Mahesh, M.V. Tejesvi, M.S. Nalini, H.S. Prakash, K.R. Kini, V. Subbiah, and H.S. Shetty, Endophytic mycoflora of inner bark of Azadirachta indica. A. Juss. Current Science 88, 2005, 218-219.

[20] I. Okane, A. Nagagiri, and T. Ito, Preliminary study of endophytic fungi in evergreen plants from Ishigaki and Iriomote islands. Osaka Research Communication, 18, 1997, 45-51.

[21] R. Rajagopal, and T.S. Suryanarayanan, Isolation of endophytic fungi from leaves of neem (Azadirachta indica). Current Science, 78, 2000, 1375-378

[22] G. Praveeen, N.K. Bohra, and D.K. Purohit, Endophytic Mycoflora of Inner Bark of Prosopis cineraria - a Key Stone Tree Species of Indian Desert. American-Eurasian Journal of Botany (1), 2008, 01-04.

[23] P.F. Cannon, and C.M. Simmons, Diversity and host preference of leaf endophytic fungi in the Iwokrama forest reserve, Guyana Mycologia 94, 2002, 210-220.

[24] M.R.L. Ramos, R.V. Fernandes, E.B. Silveria, M.D.L Manezes, V. Fernandes, and E.B. Silveria, Survey of endophytic and epiphytic fungi from coconut leaves in the North east of Brasil. II effect of the locality on the fungal population. Agrotropica 10, 1998, 1-8.

[25] J. Sun, L. Guo, W. Zang, W. Ping, and D. Chi, Diversity and ecological distribution of endophytic fungi associated with medicinal plants. Science in China series C: Life Science 51 (8), 2008, 751-759.

[26] M.V. Tejesvi, B. Mahesh, M.S. Nalini, H.S. Prakash, V. Subbaiah, K.R. Kini, and H.S. Shetty, Endophytic fungal assemblages from inner bark and twig of Terminalia arjuna W. and A. (Combretaceae). World Journal Microbiology Biotechnology 21, 2005, 1535154.

[27] D.S.S. Kumar, and K.D. Hyde, Biodiversity and tissue-recurrence of endophytic fungi in Tripterygium wilfordii. Fungal Diversity $17,2004,69-90$

[28] A. Thalavaipandian, V. Ramesh, S. Bagyalakshmi, S. Muthuramkumar, and A. Rajendran, Diversity of fungal endophytes in medicinal plants of Courtallam hills, Western Ghats, India. Mycosphere 2(5), 2011, 575-582. 